\title{
Pathogenic Elizabethkingia miricola Infection in Cultured Black-Spotted Frogs, China, 2016
}

\author{
Ruixue Hu, Junfa Yuan, Yin Meng, \\ Zhe Wang, Zemao Gu
}

Multiregional outbreaks of meningitis-like disease caused by Elizabethkingia miricola were confirmed in blackspotted frog farms in China in 2016. Whole-genome sequencing revealed that this amphibian $E$. miricola strain is closely related to human clinical isolates. Our findings indicate that $E$. miricola can be epizootic and may pose a threat to humans.

E lizabethkingia is a genus of gram-negative, nonmotile, non-spore-forming bacilli occasionally associated with human clinical infections (1-6). Although E. meningoseptica is the most commonly identified nosocomial pathogen of the genus (2), many descriptions of this species are misidentifications of E. anophelis and E. miricola (3-5). E. anophelis, initially isolated from the midgut of mosquitoes, caused a large outbreak centered in Wisconsin during 2015-2016 (5). E. miricola was found in 2003 in condensation water at the Mir space station (7). The first reported case of E. miricola infection was in a hematology patient in the United States in 2008 (8). Subsequently, E. miricola has been increasingly documented as causing bacteremia and sepsis in immunocompromised and immunocompetent patients, mostly in European countries (6). Until now, pathogenic E. miricola has seldom been isolated from Asia, and whether E. miricola can be pathogenic to animals is unknown.

The black-spotted frog, Pelophylax nigromaculatus, is a typical amphibian species, largely endemic to east Asia. Owing to the success of rearing it on an artificial diet, this frog has been widely farmed under special government approval as an edible animal in south-central China in recent years. In 2016, epidemic meningitis-like disease outbreaks in cultured black-spotted frogs occurred in separate farms. We identified E. miricola as the predominant pathogen and used whole-genome sequencing (WGS) to further characterize this Asian epizootic isolate and phylogenetically compare it with the available typical Elizabethkingia genomes.

Author affiliations: Huazhong Agricultural University, Wuhan,

China (R. Hu, J. Yuan, Y. Meng, Z. Wang, Z. Gu); Hubei

Engineering Research Center for Aquatic Animal Diseases Control and Prevention, Wuhan (R. Hu, J. Yuan, Z. Gu)

DOI: https://doi.org/10.3201/eid2312.170942

\section{The Study}

Since May 2016, many black-spotted frogs in farms in Hunan Province in south-central China have experienced an emerging, contagious disease characterized mainly by severe neurologic dysfunction. The first clinical sign is intermittent swimming in circles. Thereafter, the frogs develop signs of torticollis (Figure 1, panel A), disorientation (Video, https://wwwnc.cdc.gov/EID/article/23/12/17-0942-V1. $\mathrm{htm}$ ), and anepithymia or meteorism (Figure 1, panel E). These signs are followed by cataracts (Figure 1, panel C); proptosis or hyperemia (Figure 1, panels B, D); agitation or lethargy; and, ultimately, death. The frogs are farmed in artificial ecologic wetlands or ponds with running water and shelter (online Technical Appendix Figure 1, https:// wwwnc.cdc.gov/EID/article/23/12/17-0942-Techapp1. pdf). Most ponds in 1 farm, which share a common water supply, were infected sequentially within a short time. More than $60 \%$ of the frogs in the infected farms had signs of varying appearance, and $60 \%-90 \%$ of the diseased frogs died in the next few days or weeks. The disease continued until hibernation and returned the following spring.

During July-October 2016, we collected 213 abnormal frogs from 7 separate farms in Hunan Province, China (online Technical Appendix Figure 2). Histopathologic examination showed severe meningitis with denatured, incrassate meninges. We observed inflammatory infiltrates, moderate multifocal gliosis, and perivascular cuffing in the cerebellum (online Technical Appendix Figure 3). Results of the diagnostic tests for Batrachochytrium dendrobatidis and ranaviruses were negative (Table 1). Although we observed Myxosporidia protozoa in the gallbladder and some protists in the intestine, they were not identified as the etiologic agents, considering the proportion of infection (online Technical Appendix Figure 4).

We confirmed bacterial infections in 190 (89.2\%) of the 213 frogs; $90 \%$ were E. miricola according to the 16S rRNA gene sequence, which shared $99.36 \%-99.86 \%$ similarity with E. miricola DSM14571 (online Technical Appendix). We selected bacterial strain FL160902, isolated from frog no. 160, as the representative isolate and conducted experimental pathogenicity testing by various infection routes, including intramuscular injection, immersion infection, and cohabitation with infected frogs. All animal handling was done in compliance with the National Institutes of Health protocols (online Technical Appendix). After 2 weeks of observations 

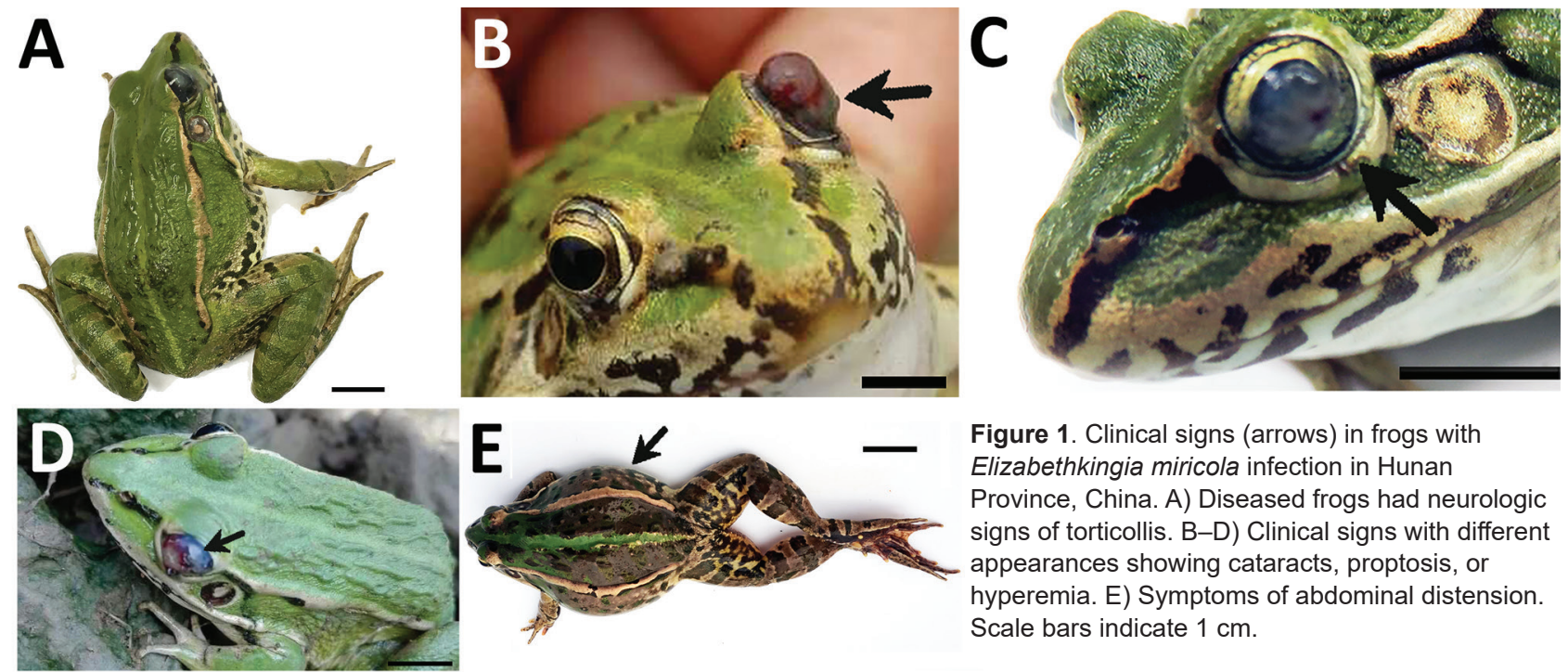

Figure 1. Clinical signs (arrows) in frogs with Elizabethkingia miricola infection in Hunan Province, China. A) Diseased frogs had neurologic signs of torticollis. B-D) Clinical signs with different appearances showing cataracts, proptosis, or hyperemia. E) Symptoms of abdominal distension. Scale bars indicate $1 \mathrm{~cm}$.
(Table 2), we found that the cumulative mortality $(10 \%-$ $70 \%)$ increased with dose in the injection trial and that $100 \%$ of frogs exposed to E. miricola by immersion died. In the cohabitation studies, $30 \%$ mortality was recorded, indicating cross-infection. Koch's postulates were satisfied by identification of isolates from dead frogs as $E$. miricola, identical to FL160902.

To characterize E. miricola FL160902, we conducted WGS with the Illumina HiSeq 2500 platform (Illumina Inc., San Diego, CA, USA), producing $2 \times 150$-bp paired-end reads. We assembled the trimmed reads using SOAPdenovo (http://soap.genomics.org.cn/soapdenovo. html). We constructed a phylogenetic tree (Figure 2) of orthologous genes using RAxML (9) with 100 bootstrap replicates to examine the evolutionary relatedness between E. miricola FL160902 (GenBank accession no. NHPR00000000) and other Elizabethkingia genomes. The results showed that FL160902 was most closely related to CSID_3000517120, a clinical isolate of E. miricola from the United States sequenced by the Centers for Disease Control and Prevention (CDC) (10), revealing the potential of E. miricola FL160902 for pathogenicity in humans.

Before WGS was commonly used, E. meningosep-

\begin{tabular}{|c|c|c|c|c|c|c|c|c|c|c|}
\hline \multirow[b]{2}{*}{ Pathogen } & \multicolumn{9}{|c|}{ Tested organ } & \multirow{2}{*}{$\begin{array}{c}\text { No. } \\
\text { positive }\end{array}$} \\
\hline & Skin & Liver & Spleen & Kidney & Brain & Intestine & Muscle & Gallbladder & Heart & \\
\hline Bacteria & NT & + & + & + & + & NT & NT & NT & NT & $190 \dagger$ \\
\hline Parasite $\ddagger$ & - & - & - & - & - & - & - & + & - & 9 \\
\hline Fungus§ & - & NT & NT & NT & NT & NT & NT & NT & NT & 0 \\
\hline Ranaviruses & NT & NT & - & - & NT & NT & - & NT & NT & 0 \\
\hline
\end{tabular}

${ }^{*} \mathrm{NT}$, not tested; +, positive; -, negative.

†Predominant bacterial infection. The results were considered positive if any one of the tested organs was positive.

$\ddagger$ Class Myxosporea.

$\S B$ atrachochytrium dendrobatidis.

\begin{tabular}{|c|c|c|c|c|c|c|c|c|c|c|}
\hline \multirow[b]{2}{*}{ Route of infection } & \multirow{2}{*}{$\begin{array}{c}\text { Concentration, } \\
\text { CFU/mL }\end{array}$} & \multirow{2}{*}{$\begin{array}{l}\text { No. frogs } \\
\text { per trial }\end{array}$} & \multicolumn{7}{|c|}{ Cumulative no. deaths, by days after exposure $\dagger$} & \multirow[b]{2}{*}{ Mortality, \% } \\
\hline & & & 2 & 4 & 6 & 8 & 10 & 12 & 14 & \\
\hline \multirow[t]{4}{*}{ Intramuscular injection $\ddagger$} & $10^{5}$ & 10 & 0 & 1 & 1 & 1 & 1 & 1 & 1 & 10 \\
\hline & $10^{6}$ & 10 & 0 & 0 & 1 & 1 & 5 & 5 & 5 & 50 \\
\hline & $10^{7}$ & 10 & 1 & 3 & 6 & 7 & 7 & 7 & 7 & 70 \\
\hline & SPSS§ & 10 & 0 & 0 & 0 & 0 & 0 & 0 & 0 & 0 \\
\hline Immersion inoculation & $10^{6}$ & 10 & 3 & 7 & 10 & 10 & 10 & 10 & 10 & 100 \\
\hline Cohabitation inoculation\# & NA & 10 & 0 & 0 & 1 & 3 & 3 & 3 & 3 & 30 \\
\hline Control & NA & 10 & 0 & 0 & 0 & 0 & 0 & 0 & 0 & 0 \\
\hline
\end{tabular}

${ }^{\star} \mathrm{NA}$, not applicable.

†Deaths after $14 \mathrm{~d}$ were not included.

łlnjection volume $200 \mu \mathrm{L}$.

$\S A n$ equivalent volume injection of $0.70 \%$ stroke-physiologic saline solution.

TImmersed for $30 \mathrm{~min}$ in E. miricola suspension.

\#Frogs in this trial cohabited with frogs previously infected with E. miricola. 
tica (previously Flavobacterium meningosepticum) was found to be separated into 2 main hybridization groups, UBI and UBII, that were $\approx 40 \%-55 \%$ interrelated; UBII could be further divided into 4 subgroups $(11,12)$. However, because the isolates from different groups are phenotypically very similar, these genomic groups remain assigned at this time to E. meningoseptica (13). In our phylogenetic tree, UBI group E. meningoseptica isolates did not group with the other Elizabethkingia spp. and were distantly related to UBII. Considering the low DNA-DNA relatedness $(<70 \%)$ between the 2 groups and phylogenomic analysis based on $\operatorname{WGS}(3,11,12)$, we propose that UBII are not E. meningoseptica. The UBII subgroups branching separately supports the view

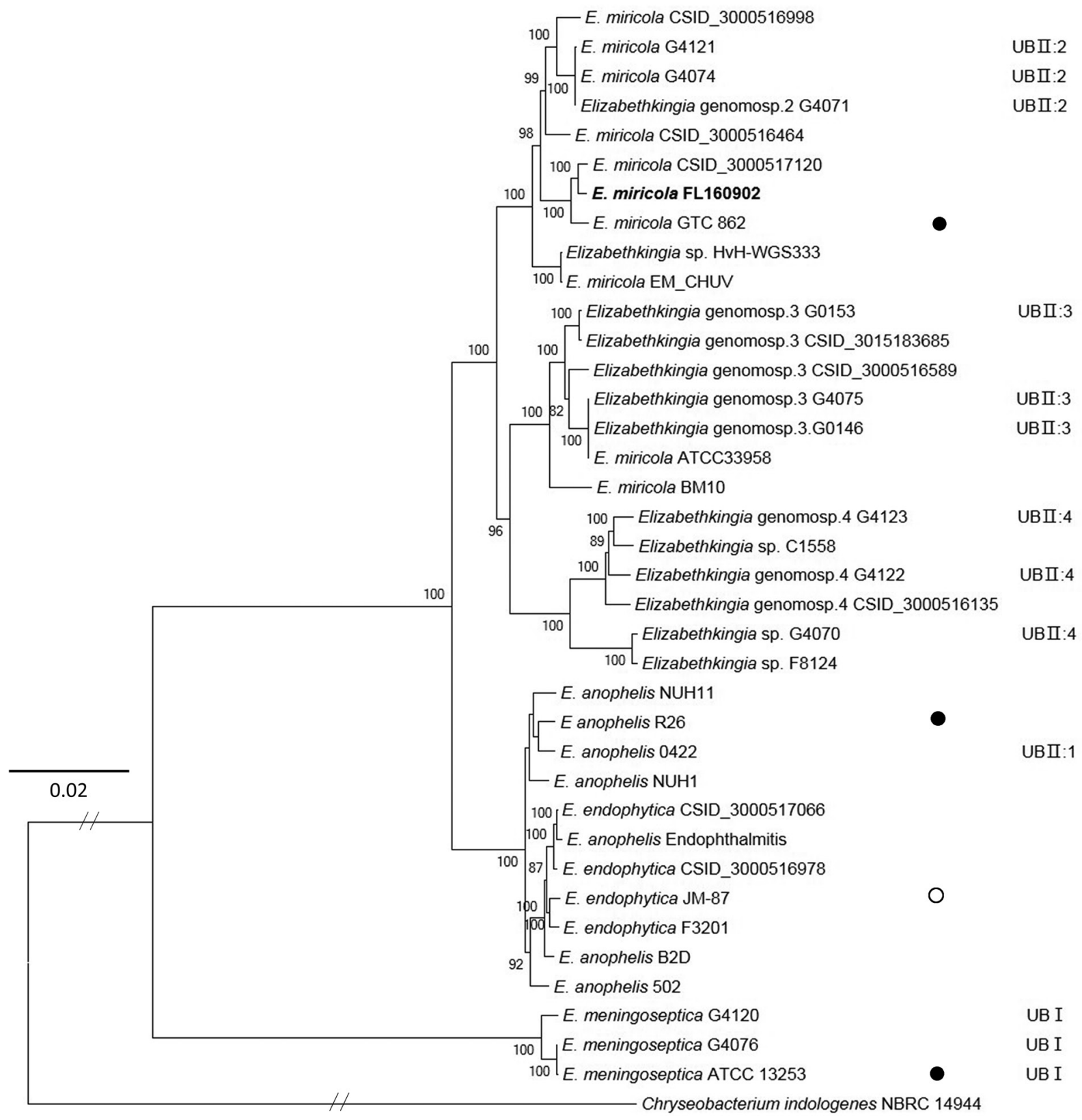

Figure 2. Maximum-likelihood phylogenetic tree of Elizabethkingia miricola FL160902 from an infected frog in Hunan Province, China, and reference genomes. The tree was constructed by using the single-copy orthologous genes of all the 38 genomes with 100 bootstrap replicates. Species identifications strictly followed the National Center for Biotechnology Information submitted names. Isolates assigned into UB groups and subgroups are according to Holmes et al. (12) and Bruun and Ursing (13). Solid circles indicate type strains; open circle indicates a former type strain. Bold indicates strain isolated in this study. Scale bar indicates nucleotide substitutions per site. 
that they are different Elizabethkingia species (3). The UBII:1 group species E. anophelis and E. endophytica formed a clade with strong support of $100 \%$, favoring the suggestion that $E$. endophytica is a later subjective synonym of E. anophelis (14). Our FL160902 isolate grouped with E. miricola, which is thought to be closely related to UBII:2 $(3,10)$. The taxonomic status of E. miricola ATCC 33958 and BM10 should be reconsidered because they clustered with UBII:3 and not with UBII:2 E. miricola species. Our results agree with Eriksen's conclusion about the genetic diversity in Elizabethkingia; a more comprehensive taxonomic system is needed to clarify the Elizabethkingia genus (3).

\section{Conclusions}

In this natural outbreak of meningitis-like disease in cultured frogs in Hunan Province, China, in 2016, E. miricola was the most predominant pathogen. The neurologic signs and pathologic brain lesions suggested that E. miricola could break through the blood-brain barrier and damage the nervous system. The etiologic analyses combined with the results of experimental challenge support the conclusion that the E. miricola strain represented by isolate FL160902 is highly contagious for frogs, especially by immersion infection. We suspect that contaminated water is the primary vehicle of transmission, considering the infection assay and the epidemiology in 1 farm with different ponds. However, diverse transmission routes might be involved because there is no obvious interconnectivity among independent farms, which needs to be investigated further. Close attention should be paid to whether this disease affects the wild population of amphibians. Our results indicated the gradual expansion of its host and suggest that amphibians may serve as a reservoir for infection in humans. Black-spotted frog farming is a major aquaculture industry in south-central China; thus, animals and humans that have close contact with infected frogs should be continually monitored for emerging E. miricola infections, even though no human E. miricola infection cases were reported related to frog consumption or farming in Hunan in 2016. Our results demonstrate a contagious disease in frogs caused by E. miricola that poses a potential zoonotic threat to humans, generating a need for consideration of the role of Elizabethkingia bacteria in public health.

\section{Acknowledgments}

We thank Junguang Ruan and the frog farmers for their cooperation with the sample collection. We also thank Dandan Zhao for parasite identification and Yang Liu for the excellent bioinformatics technical assistance.
This study was supported by China Agriculture Research System CARS-46, Hubei Agricultural Science and Technology Innovation Center (2016-620-007-001), Featuring Talents Cultivation Project (4006-4611300108), and Pre-research Foundation of Huazhong Agricultural University (52209-814058).

Ms. Hu is a PhD candidate at Huazhong Agricultural University, Wuhan, China. Her primary research interest is pathogenic microbiology and infectious diseases of amphibians.

\section{References}

1. Kim KK, Kim MK, Lim JH, Park HY, Lee ST. Transfer of Chryseobacterium meningosepticum and Chryseobacterium miricola to Elizabethkingia gen. nov. as Elizabethkingia meningoseptica comb. nov. and Elizabethkingia miricola comb. nov. Int J Syst Evol Microbiol. 2005;55:1287-93. http://dx.doi.org/10.1099/ijs.0.63541-0

2. Moore LSP, Owens DS, Jepson A, Turton JF, Ashworth S, Donaldson $\mathrm{H}$, et al. Waterborne Elizabethkingia meningoseptica in adult critical care. Emerg Infect Dis. 2016;22:9-17. http://dx.doi.org/10.3201/eid2201.150139

3. Eriksen HB, Gumpert H, Faurholt CH, Westh H. Determination of Elizabethkingia diversity by MALDI-TOF mass spectrometry and whole-genome sequencing. Emerg Infect Dis. 2017;23:320-3. http://dx.doi.org/10.3201/eid2302.161321

4. Lau SK, Chow WN, Foo CH, Curreem SO, Lo GC, Teng JL, et al. Elizabethkingia anophelis bacteremia is associated with clinically significant infections and high mortality. Sci Rep. 2016;6:26045. http://dx.doi.org/10.1038/srep26045

5. Perrin A, Larsonneur E, Nicholson AC, Edwards DJ, Gundlach KM, Whitney AM, et al. Evolutionary dynamics and genomic features of the Elizabethkingia anophelis 2015 to 2016 Wisconsin outbreak strain. Nat Commun. 2017;8:15483. http://dx.doi.org/10.1038/ ncomms 15483

6. Opota O, Diene SM, Bertelli C, Prod'hom G, Eckert P, Greub G. Genome of the carbapenemase-producing clinical isolate Elizabethkingia miricola EM_CHUV and comparative genomics with Elizabethkingia meningoseptica and Elizabethkingia anophelis: evidence for intrinsic multidrug resistance trait of emerging pathogens. Int J Antimicrob Agents. 2017;49:93-7. http://dx.doi.org/10.1016/j.ijantimicag.2016.09.031

7. Li Y, Kawamura Y, Fujiwara N, Naka T, Liu H, Huang X, et al. Chryseobacterium miricola sp. nov., a novel species isolated from condensation water of space station Mir. Syst Appl Microbiol. 2003;26:523-8. http://dx.doi.org/10.1078/072320203770865828

8. Green O, Murray P, Gea-Banacloche JC. Sepsis caused by Elizabethkingia miricola successfully treated with tigecycline and levofloxacin. Diagn Microbiol Infect Dis. 2008;62:430-2. http://dx.doi.org/10.1016/j.diagmicrobio.2008.07.015

9. Stamatakis A. RAxML version 8: a tool for phylogenetic analysis and post-analysis of large phylogenies. Bioinformatics. 2014;30:1312-3. http://dx.doi.org/10.1093/bioinformatics/btu033

10. Nicholson AC, Humrighouse BW, Graziano JC, Emery B, McQuiston JR. Draft genome sequences of strains representing each of the Elizabethkingia genomospecies previously determined by DNA-DNA hybridization. Genome Announc. 2016;4:e0045-16. http://dx.doi.org/10.1128/ genomeA.00045-16

11. Ursing J, Bruun B. Genetic heterogeneity of Flavobacterium meningosepticum demonstrated by DNA-DNA hybridization. Acta Pathol Microbiol Immunol Scand B. 1987;95:33-9.

12. Holmes B, Steigerwalt AG, Nicholson AC. DNA-DNA hybridization study of strains of Chryseobacterium, Elizabethkingia and Empedobacter and of other usually 
indole-producing non-fermenters of CDC groups IIc, IIe, IIh and IIi, mostly from human clinical sources, and proposals of Chryseobacterium bernardetii sp. nov., Chryseobacterium carnis sp. nov., Chryseobacterium lactis sp. nov., Chryseobacterium nakagawai sp. nov. and Chryseobacterium taklimakanense comb. nov. Int J Syst Evol Microbiol. 2013;63:4639-62. http://dx.doi.org/10.1099/ijs.0.054353-0

13. Bruun B, Ursing J. Phenotypic characterization of Flavobacterium meningosepticum strains identified by DNA-DNA hybridization. Acta Pathol Microbiol Immunol Scand B. 1987;95:41-7.
14. Doijad S, Ghosh H, Glaeser S, Kämpfer P, Chakraborty T. Taxonomic reassessment of the genus Elizabethkingia using wholegenome sequencing: Elizabethkingia endophytica Kämpfer et al. 2015 is a later subjective synonym of Elizabethkingia anophelis Kämpfer et al. 2011. Int J Syst Evol Microbiol. 2016;66:4555-9. http://dx.doi.org/10.1099/ijsem.0.001390

Address for correspondence: Zemao Gu, Huazhong Agricultural University-College of Fisheries, No. 1 Shizi Mountain St, Hongshan District Wuhan, Hubei 430070, China; email: guzemao@mail.hzau.edu.cn

\section{December 2014: Zoonoses}

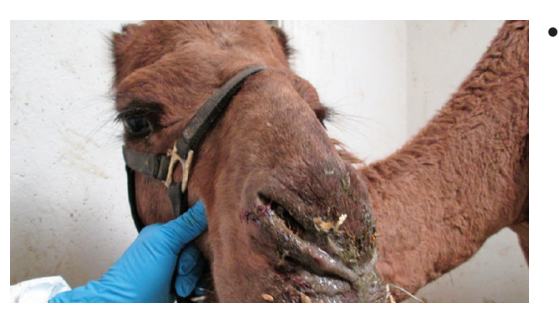

- Variably Protease-Sensitive Prionopathy, a Unique Prion Variant with Inefficient Transmission Properties

- Geographic Divergence of Bovine and Human Shiga Toxin-Producing Escherichia coli O157:H7 Genotypes, New Zealand

- Bacterial Pathogens Associated with Hidradenitis Suppurativa, France

- Replication and Shedding of MERS-CoV in Upper Respiratory Tract of Inoculated Dromedary Camels

- Transmission Characteristics of Variably ProteaseSensitive Prionopathy

- Seroconversion for Infectious Pathogens among UK Military Personnel Deployed to Afghanistan, 2008-2011

- Circulation of Reassortant Influenza A(H7N9) Viruses in Poultry and Humans, Guangdong

- Molecular Evolution of Peste des Petits Ruminants Virus Province, China, 2013

- Effects of Knowledge, Attitudes, and Practices of Primary Care Providers on Antibiotic Selection, United States

- Accuracy of Herdsmen Reporting versus Serologic Testing for Estimating Foot-and-Mouth Disease Prevalence

- Residual Infestation and Recolonization during Urban Triatoma infestans Bug Control Campaign, Peru

- Two Anaplasma phagocytophilum Strains in Ixodes scapularis Ticks, Canada

- Francisella tularensis Bacteria Associated with Feline Tularemia in the United States

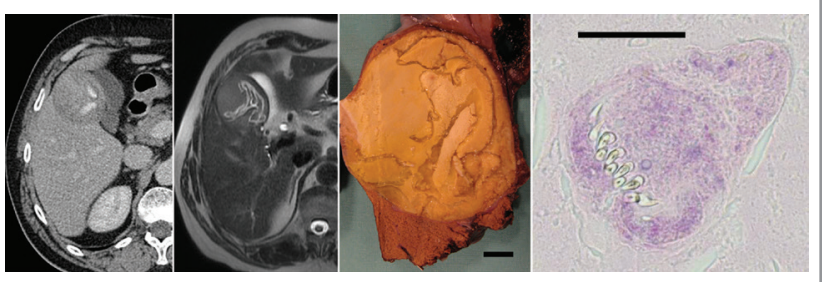

- Avian Bornavirus in Free-Ranging Psittacine Birds, Brazil

- Gouleako and Herbert Viruses in Pigs, Republic of Korea, 2013

- Human Infection with Influenza Virus $\mathrm{A}(\mathrm{H} 10 \mathrm{~N} 8)$ from Live Poultry Markets, China, 2014

- Molecular Epidemiology of Influenza A(H1N1)pdm09 Virus among Humans and Swine, Sri Lanka

- Novel Amdoparvovirus Infecting Farmed Raccoon Dogs and Arctic Foxes

- Novel Porcine Epidemic Diarrhea Virus Variant with Large Genomic Deletion, South Korea

- MERS Coronavirus Neutralizing Antibodies in Camels, Eastern Africa, 1983-1997

- Equine Influenza $A(H 3 N 8)$ Virus Infection in Cats

- Echinococcus ortleppi Infections in Humans and Cattle, France

- Human Hantavirus Infections in the Netherlands

- Mycobacterium Species Related to M. leprae and M. lepromatosis from Cows with Bovine Nodular Thelitis

- Human Metapneumovirus Infection in Chimpanzees, United States

- Putative New West Nile Virus Lineage in Uranotaenia unguiculata Mosquitoes, Austria, 2013

- Novel Bluetongue Virus in Goats, Corsica, France, 2014

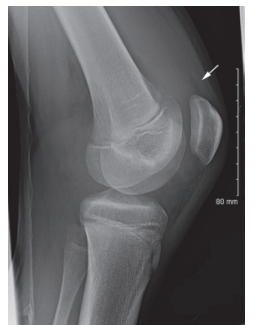

